AUTHOR CORRECTION OPEN

\title{
Author Correction: Sarcolab pilot study into skeletal muscle's adaptation to longterm spaceflight
}

Jörn Rittweger $\mathbb{D D}^{1,2}$, Kirsten Albracht ${ }^{3,4}$, Martin Flück $\mathbb{D D}^{5}$, Severin Ruoss $\mathbb{D D}^{5}$, Lorenza Brocca $\mathbb{D}^{6}$, Emanuela Longa ${ }^{6}$, Manuela Moriggi ${ }^{7}$, Olivier Seynnes ${ }^{8}$, Irene Di Giulio ${ }^{9}$, Leonardo Tenori ${ }^{10}$, Alessia Vignoli ${ }^{11}$, Miriam Capri (D) $^{12}$, Cecilia Gelfi ${ }^{13}$, Claudio Luchinat $^{11}$, Claudio Franceschi ${ }^{12}$, Roberto Bottinelli ${ }^{6,14}$, Paolo Cerretelli ${ }^{7}$ and Marco Narici ${ }^{15}$

npj Microgravity (2018)4:23 ; doi:10.1038/s41526-018-0058-8

Correction to: npj Microgravity https://doi.org/10.1038/s41526018-0052-1, Article Published online 17 Sep 2018

The original version of this Article contained an error in the spelling of the author Claudio Franceschi, which was incorrectly given as Claudio Francheschi. This has now been corrected in both the PDF and HTML versions of the Article.

Open Access This article is licensed under a Creative Commons Attribution 4.0 International License, which permits use, sharing adaptation, distribution and reproduction in any medium or format, as long as you give appropriate credit to the original author(s) and the source, provide a link to the Creative Commons license, and indicate if changes were made. The images or other third party material in this article are included in the article's Creative Commons license, unless indicated otherwise in a credit line to the material. If material is not included in the article's Creative Commons license and your intended use is not permitted by statutory regulation or exceeds the permitted use, you will need to obtain permission directly from the copyright holder. To view a copy of this license, visit http://creativecommons. org/licenses/by/4.0/.

(c) The Author(s) 2018

\footnotetext{
${ }^{1}$ Institute of Aerospace Medicine, German Aerospace Center (DLR), Cologne, Germany; ${ }^{2}$ Department of Pediatrics and Adolescent Medicine, University of Cologne, Cologne, Germany; ${ }^{3}$ Faculty of Medical Engineering and Technomathematics, FH Aachen University of Applied Science Aachen, Aachen, Germany; ${ }^{4}$ Institute of Biomechanics and Orthopaedics, German Sport University, Cologne, Germany; ${ }^{5}$ Department of Orthopaedics, University of Zürich, Zürich, Switzerland; ${ }^{6}$ Department of Molecular Medicine, University of Pavia, Pavia, Italy; ${ }^{7}$ CNR-IBFM, Segrate, MI, Italy; ${ }^{8}$ Department of Physical Performance, Norwegian School of Sport Sciences, Oslo, Norway; ${ }^{9}$ Centre for Human and Applied Physiological Sciences, King's College London, London, UK; ${ }^{10}$ Department of Experimental and Clinical Medicine, University of Florence, Florence, Italy; ${ }^{11} \mathrm{CERM}$ Centro di Ricerca di Risonanze Magnetiche, Florence, Italy; ${ }^{12}$ Department of Experimental, Diagnostic and Specialty Medicine, University of Bologna, Bologna, Italy; ${ }^{13}$ Department of

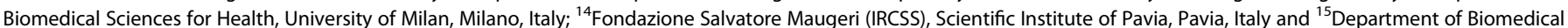
Sciences, University of Padova, Padova, Italy

Correspondence: Jörn. Rittweger (Joern.Rittweger@dlr.de)
}

Published online: 24 October 2018 